\title{
Acetalization of glycerol with acetone over various metal-modified SBA-15 catalysts
}

\author{
Sarthani Ammaji ${ }^{1}$ G. Srinivasa Rao ${ }^{1} \cdot$ Komandur V. R. Chary ${ }^{1}$
}

Received: 9 August 2017 / Accepted: 14 March 2018 / Published online: 24 April 2018

(c) The Author(s) 2018

\begin{abstract}
Several catalysts containing metals such as $\mathrm{Al}, \mathrm{Zr}$, Ti and $\mathrm{Nb}$ were incorporated in SBA-15 with $\mathrm{Si} / \mathrm{M}$ ratio $=20$ using the hydrothermal process. These catalysts were evaluated for their reactivity during acid-catalyzed condensation of glycerol with acetone to yield a mixture of branched compounds, namely (2,2-dimethyl- [1,3] dioxane-4-yl)-methanol (solketal) and 2,2-dimethyl- [1,3] dioxane-5-ol, which are being used as fuel additives. The synthesised catalyst samples were characterized by ICP-AES analysis, $\mathrm{N}_{2}$ adsorption-desorption measurements, X-ray diffraction, FT-IR, SEM-EDX, UV-visible diffuse reflectance spectroscopy, TPD of ammonia and ex situ pyridine-adsorbed FT-IR spectroscopy. The various characterization results confirm that metal oxides were incorporated in the pore wall of the SBA-15 matrices. The results of $\mathrm{NH}_{3}$-TPD and ex situ adsorbed pyridine FT-IR analyses showed that the acidity of the samples increased after incorporation of metal into the pure SBA-15 samples. Among various metals incorporated into the SBA-15, the Nb-SBA-15 $(\mathrm{Si} / \mathrm{Nb}=20)$ showed higher catalytic activity toward the acetalization of glycerol in liquid phase compared to that of other samples investigated. Under the optimal reaction conditions, the Nb-SBA-15 $(\mathrm{Si} / \mathrm{Nb}=20)$ exhibited $95 \%$ glycerol conversion with $100 \%$ solketal selectivity. The catalyst reusability studies indicated that the Nb-SBA-15 sample is regenerable and highly stable in the acetalization of glycerol.
\end{abstract}

Keywords Glycerol $\cdot$ Acetalization $\cdot$ Solketal $\cdot$ SBA-15 $\cdot$ Metal-incorporated SBA-15

\section{Introduction}

The world energy crisis has become an exceptionally crucial topic of research in recent years with diminishing petroleum reserve. Thus, biomass has become the only promising renewable resource of energy, which is environmental friendly, industrially feasible, biodegradable and offers less emission of greenhouse gases during combustion, to the sustainable development of society. With the increase in energy utilization in transport and domestic sectors, the issue of energy security and climate change has gained much attention for exploration of new catalysts. Considering the

Electronic supplementary material The online version of this article (https://doi.org/10.1007/s13203-018-0197-6) contains supplementary material, which is available to authorized users.

Komandur V. R. Chary

charykvr@gmail.com

1 Catalysis and Fine Chemicals Division, CSIR-Indian Institute of Chemical Technology, Uppal Road, Tarnaka, Hyderabad, India limited resource of petroleum and natural gas coupled with price volatility, there have been substantial research efforts on finding alternative renewable sources. A variety of alternative energy sources have been developed, such as hydroelectric energy, wind power, geothermal energy and solar energy. However, it should be realized that the application of these energy sources might take a longer time than expected. The development of efficient processes to convert biomass resource into liquid fuels would be an important research area in the next few decades. Of particular interest is the utilization of triglycerides of vegetable or animal oil for the production of biodiesel as a liquid fuel. It is a process of transesterification of triglycerides with methanol in the presence of acidic or basic catalysts. Biodiesel has been considered to be one of the most promising alternatives to fossil fuel resources [1-4]. In addition, the process produces substantial amounts of glycerol as the main by-product, which is equivalent to $10 \mathrm{wt} \%$ of the total biodiesel production [5].

Glycerol is currently surplus in the biodiesel industry and is available at very low prices. Presently, it has very limited applications in the area of cosmetics, soaps and medicines 
[6]. Therefore, the conversion of glycerol into value- added products is an attractive proposition in the current scenario. Glycerol is considered as one of the most important platform chemicals to produce various chemicals such as acrolein, acrylic acid, propane diols, glyceraldehyde, glyceric acid, dihydroxy acetone and acetylated glycerol, using various chemical transformations [7, 8]. Among the value addition processes of glycerol, the acetalization of glycerol with an aldehyde or a ketone is an important transformation to produce oxygenated compounds such as acetals and solketal [9]. In general, the acetalization of glycerol with acetone gives branched oxygenated compounds, namely (2,2-dimethyl- $[1,3]$ dioxane-4-yl)-methanol (solketal) and 2,2-dimethyl- [1,3] dioxane-5-ol. Solketal is an excellent component for the formulation of gasoline, as ignition accelerator and antiknock additives in combustion engines, biodiesel fuels and also has great industrial applications in cosmetics, fragrances and pharmaceuticals [10].

This reaction generally involves the use of solid acid catalysts such as amberlyst, zeolites and supported heteropoly acids [11]. However, these catalysts find limited usage due to poor thermal and textural properties and suffer from low catalytic activity toward acetalization reactions [12]. Our earlier research efforts on acetalization of glycerol with acetone to solketal over molybdenum phosphate supported on SBA-15 catalyst yielded solketal with a high yield of 98\% [13]. However, this catalytic system faces severe problem in regaining its original activity during reaction and regeneration, due to leaching of the active species into the reaction mixture. Therefore, lot of efforts has been made to design the catalyst with high catalytic activity along with stability during the reaction conditions. In this context, metal oxide catalysts received a great deal of attention due to their excellent catalytic behavior in terms of activity, stability and regenerability in the reactions.

Recently, the discovery of mesoporous materials has stimulated extensive interest because of their wider applications in catalysis, separation and adsorption due to their high specific surface area, uniform pore size distribution and large pore size. Among the mesoporous materials, SBA-15 materials have received particular attention due to various properties such as hydrothermal and thermal stability, larger pore size and thicker pore wall, which makes it a promising catalytic material [14-16]. However, pure SBA-15 materials are not as active in catalyzing chemical reactions as would be desired due to lack of various properties such as redox and acidity/basicity, and this could be achieved by incorporating various transition metals into the mesoporous SBA-15 matrix [17]. However, various metal ions of $\mathrm{Al}, \mathrm{Ti}, \mathrm{Zr}$ and $\mathrm{Nb}$ are well known for their application in the acid-catalyzed reaction such as dehydration and esterification $[18,19]$. In the present work, for the metal incorporation into SBA-15, the direct synthesis method was chosen since this method allows metals to disperse uniformly into the pores of SBA15 [20, 21]. Hence, our interest is to synthesize these metal ions-incorporated SBA-15 materials into the framework for the acetalization of glycerol into solketal.

In the present investigation, we report a systematic study on the characterization and application of various metals $[\mathrm{Zr}, \mathrm{Al}, \mathrm{Ti}, \mathrm{Nb}]$ incorporated into the SBA- 15 catalyst for the acetalization of glycerol with acetone to produce solketal. The synthesized catalysts were characterized by various techniques such as $\mathrm{N}_{2}$ sorption analysis, $\mathrm{X}$-ray diffraction, FT-IR, SEM, UV-DRS, $\mathrm{NH}_{3}$-TPD and ex situ adsorbed pyridine FT-IR methods. The purpose of this work is to examine the catalytic properties of the metals-incorporated SBA-15 catalysts for the acetalization of glycerol with acetone and also to find the relation between the surface structural properties and catalytic functionalities during acetalization of glycerol.

\section{Experimental section}

\section{Preparation of pure and metal-incorporated SBA-15}

The pure and M-SBA-15 materials (where $\mathrm{M}=\mathrm{Al}, \mathrm{Zr}$, Ti and $\mathrm{Nb} ; \mathrm{Si} / \mathrm{M}$ ratio $=20$ ) were synthesized according to a previously reported procedure [22-24]. The zirconium (IV) n-propoxide solution (70 wt\% in 1-propanol, Aldrich), tetraisopropyl o-titanate (TiPOT, > 98\%, Merc), niobium (V) chloride (99\%, Sigma-Aldrich) and aluminum isopropoxide (Sigma-Aldrich) were used as precursors for preparing the M-SBA-15 materials, where $\mathrm{M}=\mathrm{Zr}$, $\mathrm{Ti}, \mathrm{Nb}$ and $\mathrm{Al}$ respectively. Pluronic P123 (Aldrich, MW =5800) and tetraethyl o-silicate (TEOS, 98\%, Aldrich) were used as template and silica source, respectively.

In a typical synthesis, $18 \mathrm{~g}$ of P123 was dissolved in the mixture of $140 \mathrm{~g}$ of deionized water; $10.5 \mathrm{~g}$ of hydrochloric acid $(\mathrm{HCl}, 37 \%$, Hartim) and the calculated amount of metal precursors were added at $40{ }^{\circ} \mathrm{C}$. The $\mathrm{HCl}$ was not used in the case of niobium-incorporated SBA-15 samples. Then, the TEOS was added very slowly (dropwise addition) to the solution. Thereafter, this mixture was stirred at $40{ }^{\circ} \mathrm{C}$ for $24 \mathrm{~h}$ and then transformed into Teflon-lined autoclave and kept at $100{ }^{\circ} \mathrm{C}$ for another $24 \mathrm{~h}$ in static conditions. Then, the product mixture was filtered and washed with a large amount of deionized water followed by drying at $100{ }^{\circ} \mathrm{C}$ in an oven for $24 \mathrm{~h}$. The as-synthesized metal-incorporated SBA-15 samples were calcined at $500{ }^{\circ} \mathrm{C}$ for $5 \mathrm{~h}$ in air using a muffle furnace. The synthesized various metals-incorporated SBA15 samples are represented as M-SBA-15, where $\mathrm{M}$ denotes the metal such as $\mathrm{Nb}, \mathrm{Zr}$, Ti and Al. The pure SBA-15 material was obtained by the same procedure as described previously except for the usage of the metal precursor. 


\section{Catalyst characterization}

Powder X-ray diffraction patterns of SBA-15 and metalincorporated SBA-15 catalysts were recorded with Bruker $\mathrm{D}_{2}$ phaser $\mathrm{X}$-ray diffractometer using $\mathrm{Cu} \mathrm{K} \alpha$ radiation $(1.5406 \AA)$ at $40 \mathrm{kV}$ and $30 \mathrm{~mA}$ with high-resolution Lynxeye detector. The measurements were recorded in steps of $0.045^{\circ}$ with a step size of $0.5 \mathrm{~s}$ in the range of $2^{\circ}-65^{\circ}$. The FT-IR spectra of the catalysts were recorded on an IR (Model: GC-FT-IR Nicolet 670) spectrometer by the KBr disc method at room temperature. Scanning electron microscope (SEM) images were recorded on Zeiss microscope to investigate the surface morphology.

Pore size distribution measurements were performed on Autosorb-1 instrument (Quantachrome, USA) using the nitrogen physisorption method. The UV-Vis diffused reflectance spectra were recorded on a GBC UV-visible Cintra $10_{\mathrm{e}}$ spectrometer with an integrating sphere reflectance accessory. The spectra were recorded in air at room temperature and the data were transformed according to the Kubelka-Munk equation $f(R)=(1-R \alpha)^{2} / 2 R \alpha$.

The $\mathrm{NH}_{3}$-TPD experiments were conducted on Autochem 2910 instrument. The acidity of the parent SBA-15 and metal-incorporated SBA-15 catalysts was determined by temperature-programmed desorption ammonia equipped with thermal conductivity detector TCD using $\mathrm{He}$ as a carrier gas. In all the experiments, $100 \mathrm{mg}$ of oven-dried sample was out-gassed at $250{ }^{\circ} \mathrm{C}$ for $1 \mathrm{~h}$ in flowing $\mathrm{He}$ gas $\left(50 \mathrm{ml} \mathrm{min}{ }^{-1}\right)$ and then cooled down to room temperature and then the sample was saturated with $10 \% \mathrm{NH}_{3}-\mathrm{He}$ for 45 min. After saturation with ammonia, the sample was flushed in He flow for $1 \mathrm{~h}$ at $100{ }^{\circ} \mathrm{C}$ to remove physisorbed ammonia. The temperature of the furnace was then brought down to $50{ }^{\circ} \mathrm{C}$ before starting the analysis. The desorption of ammonia was recorded with a temperature program from ambient temperature to $700{ }^{\circ} \mathrm{C}$ with a heating rate of $10{ }^{\circ} \mathrm{C}$ $\mathrm{min}^{-1}$. The amount of $\mathrm{NH}_{3}$ desorbed was calculated using the GRAMS/32 software.

The metals $(\mathrm{Nb}, \mathrm{Zr}, \mathrm{Ti}, \mathrm{Al})$ and $\mathrm{Si}$ composition of the catalysts were analyzed by elemental analysis (ICP-AES M/s Thermo Scientific iCAP6500 DU) by dissolving the sample in aqua regia along with a few drops of hydrofluoric acid in a microwave oven for $2 \mathrm{~h}$ and further diluted with de-ionized water to analyze the metal $(\mathrm{Nb}, \mathrm{Zr}, \mathrm{Ti}, \mathrm{Al})$ content. This enables finding the actual metals $(\mathrm{Nb}, \mathrm{Zr}, \mathrm{Ti}, \mathrm{Al})$ to $\mathrm{Si}$ mole ratio in the catalysts.

The Brønsted and Lewis acidic sites of SBA-15 and metal-incorporated SBA- 15 catalysts were investigated by ex situ pyridine adsorption study using the FT-IR spectra recorded in absorbance mode in the wavelength range from 1400 to $1600 \mathrm{~cm}^{-1}$. Before adsorption of pyridine, the sample was preheated at $300{ }^{\circ} \mathrm{C}$ for $1 \mathrm{~h}$ in the furnace to remove the absorbed water in the sample. Thereafter, the activated samples were cooled to ambient temperature and saturated with pyridine under $\mathrm{N}_{2}$ flow at $200{ }^{\circ} \mathrm{C}$. The FT-IR spectra of the catalysts were recorded on IR (Model: GC-FT-IR Nicolet 670) spectrometer using the $\mathrm{KBr}$ disk method at room temperature.

\section{Catalytic reaction}

The liquid phase acetalization of glycerol with acetone was accomplished under solvent-free condition at atmospheric pressure and room temperature in a $25 \mathrm{ml}$ round bottom flask with a magnetic stirrer using $100 \mathrm{mg}$ of catalyst and the required amount of acetone $(3 \mathrm{mmol})$ and glycerol $(1 \mathrm{mmol})$. Prior to the reaction, the catalyst was activated at $200{ }^{\circ} \mathrm{C}$ for $1 \mathrm{~h}$ in a muffle furnace. $1 \mathrm{mmol}$ of glycerol and $3 \mathrm{mmol}$ acetone was added to the $25 \mathrm{ml}$ round bottom flask containing $100 \mathrm{mg}$ catalyst. This reaction mixture was stirred for $1 \mathrm{~h}$ and the catalyst was separated by filtration. The filtrate was collected systematically for analysis using a gas chromatograph GC-2014 (Shimadzu) equipped with a DB-wax 123-7033 (Agilent) capillary column (0.32 mm i.d., $30 \mathrm{~m}$ long) and a flame ionization detector (FID).

\section{Results and discussion}

\section{Chemical composition}

ICP-AES analysis was used to determine the quantitative amount of metal present in the samples and the results are illustrated in Table 1. The analysis results showed that various metal-incorporated SBA-15 samples had the Si/M ratio in the range of 17-22 and it was quite consistent with the theoretically calculated $\mathrm{Si} / \mathrm{M}$ ratio $(\mathrm{Si} / \mathrm{M}$ ratio $=20)$ employed during the catalyst preparation. Hence, this result confirmed the existence of the metals in the various samples. In addition, SEM-EDAX analysis results are (Table 1) also in good agreement with the ICP-AES results.

\section{Nitrogen adsorption-desorption analysis}

Figure 1 shows the nitrogen adsorption-desorption analysis of the pure SBA-15 and metal-incorporated SBA-15 samples. The isotherm of pure SBA-15 and metal-incorporated SBA-15 sample showed typical type IV nitrogen adsorption-desorption isotherms with $\mathrm{H} 1$ hysteresis loop according to the IUPAC classification. This result confirmed the existence of the hexagonal arrangement of mesopores in all the samples and this was not affected even after incorporation of the metals into the parent SBA-15. However, in the case of the metal-incorporated SBA-15 sample, the position and shape of the hysteresis loop of all samples changed depending on the metal incorporated in the SBA- 15 . The hysteresis

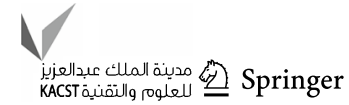


Table 1 Textural properties and TPD profiles of the various M-SBA-15 samples

\begin{tabular}{|c|c|c|c|c|c|c|c|}
\hline Name of the sample & $\begin{array}{l}\text { Surface area } \\
\left(\mathrm{m}^{2} / \mathrm{g}\right)\end{array}$ & $\begin{array}{l}\text { Pore volume } \\
(\mathrm{cc} / \mathrm{g})\end{array}$ & $\begin{array}{l}\text { Average pore } \\
\text { diameter (§̊) }\end{array}$ & $\mathrm{Si} / \mathrm{M}$ ratio $^{\mathrm{a}}$ & $\mathrm{Si} / \mathrm{M}$ ratio $^{\mathrm{b}}$ & $\mathrm{T}_{\max }^{\mathrm{c}}\left({ }^{\circ} \mathrm{C}\right)$ & $\begin{array}{l}\mathrm{NH}_{3} \\
\text { desorbed } \\
(\mu \mathrm{mol} / \mathrm{g})\end{array}$ \\
\hline SBA-15 & 830 & 1.34 & 63.4 & - & - & 140 & - \\
\hline $\mathrm{Zr}-\mathrm{SBA}-15$ & 715 & 0.80 & 40.3 & 22 & 18 & 450 & 252 \\
\hline Nb-SBA-15 & 773 & 0.83 & 54.5 & 19 & 20 & 580 & 316 \\
\hline Ti-SBA-15 & 672 & 0.97 & 39.1 & 21 & 19 & 563 & 180 \\
\hline Al-SBA-15 & 620 & 1.03 & 28.5 & 18 & 19 & 350 & 140 \\
\hline Spent Zr-SBA-15 & 550 & 0.62 & 35.5 & 19 & 17 & 560 & 219 \\
\hline Spent Nb-SBA-15 & 590 & 0.69 & 47.7 & 17 & 17 & 438 & 260 \\
\hline
\end{tabular}

${ }^{\mathrm{a} C a l c u l a t e d}$ from the ICP-AES analysis

${ }^{\mathrm{b}}$ Calculated from the SEM-EDX analysis

${ }^{\mathrm{c}}$ Ammonia desorbed temperature

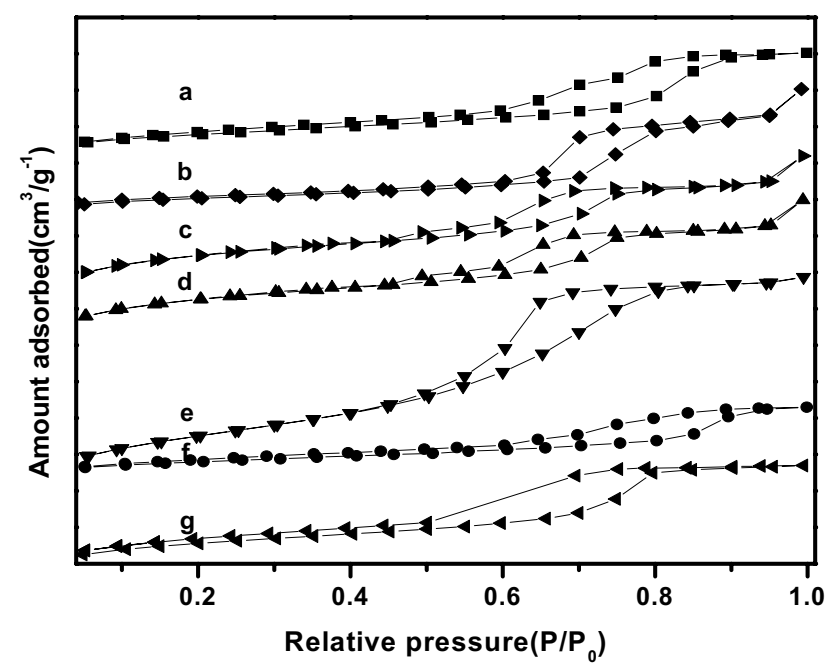

Fig. 1 Nitrogen adsorption-desorption isotherms of various M/SBA$15(\mathrm{Si} / \mathrm{M}=20)$ catalysts. a Pure SBA- 15, b $\mathrm{Zr}-\mathrm{SBA}-15$, c Nb-SBA15, d Ti-SBA-15, e Al-SBA-15, f spent Nb-SBA-15 and g spent $\mathrm{Zr}-$ SBA-15

loop for all the samples was shifted to low relative pressure approximately in the range of 0.4 and 0.7 , suggesting the decrease in the pore size of the parent SBA-15. This phenomenon can be explained by the occupation of metals in the mesopores of pure SBA-15, which decreased the pore size of the parent SBA-15.

The BJH pore size distribution analysis of the pure SBA-15 and metal-incorporated SBA-15 are shown in Fig. S1. From (Fig. S1, Supplementary Information), it is observed that all samples showed a narrow pore size distribution around $50-80 \AA$. The textural properties of all the samples determined by nitrogen sorption experiments are summarized in Table 1. It is interesting to see that all the samples have shown unimodal pore size distribution with clear indication of shift in the peak positions. These peak positions depend mainly on the nature of metal incorporated in SBA-15. All of the synthesized SBA-15-based materials showed higher specific surface areas $\left(620-830 \mathrm{~m}^{2} / \mathrm{g}\right)$ and porosity $\left(0.8-0.6 \mathrm{~cm}^{3} / \mathrm{g}\right)$ as compared to the bare SBA-15. After incorporation of the metals into the parent SBA-15, the surface area of the sample decreased compared to SBA-15 due to blocking of the pores of SBA-15. Among the samples investigated, $\mathrm{Nb}-\mathrm{SBA}-15$ showed the highest surface area $\left(772 \mathrm{~m}^{2} / \mathrm{g}\right)$ with $0.82 \mathrm{cc} / \mathrm{g}$ total pore volume, whereas Al-SBA-15 showed the lowest surface area $\left(620 \mathrm{~m}^{2} / \mathrm{g}\right)$ with $1.03 \mathrm{cc} / \mathrm{g}$ total pore volume. Decreasing surface area is associated with narrower hysteresis loops in comparison to bare SBA-15. The pore size distribution of spent catalysts (In Fig. S1, Supplementary Information) reveals that the surface area and pore size distribution of the parent catalysts decreased considerably after the reaction.

\section{Low-angle XRD analysis}

The low-angle XRD patterns of pure SBA-15 and various M-SBA-15 samples are shown in Fig. 2. The pure SBA-15 sample showed diffraction lines at $2 \theta=0.92,1.64$ and 1.85 which can be indexed to the characteristic (100), (110) and (200) planes of SBA-15 respectively, confirming the formation of hexagonally ordered mesoporous structure with p6mm symmetry. The characteristic peak of the M-SBA-15 related to the (100) plane was shifted compared with the pure SBA-15 sample in the low-angle XRD pattern, depending on the metal incorporated. However, after introduction of metals into the pure SBA-15, the intensities of the peaks decreased due to occupation of mesopores of the SBA-15 by metals. Although the metal loadings of the SBA-15 are same $(\mathrm{Si} / \mathrm{M}=20)(\mathrm{M}=\mathrm{Zr}, \mathrm{Al}, \mathrm{Ti}$ and $\mathrm{Nb})$ in all the samples, a clear change in the peak intensity and shift can by noticed. This might be due to restructuring of silica and metal precursors, during the step of absorption in the solution. However, 


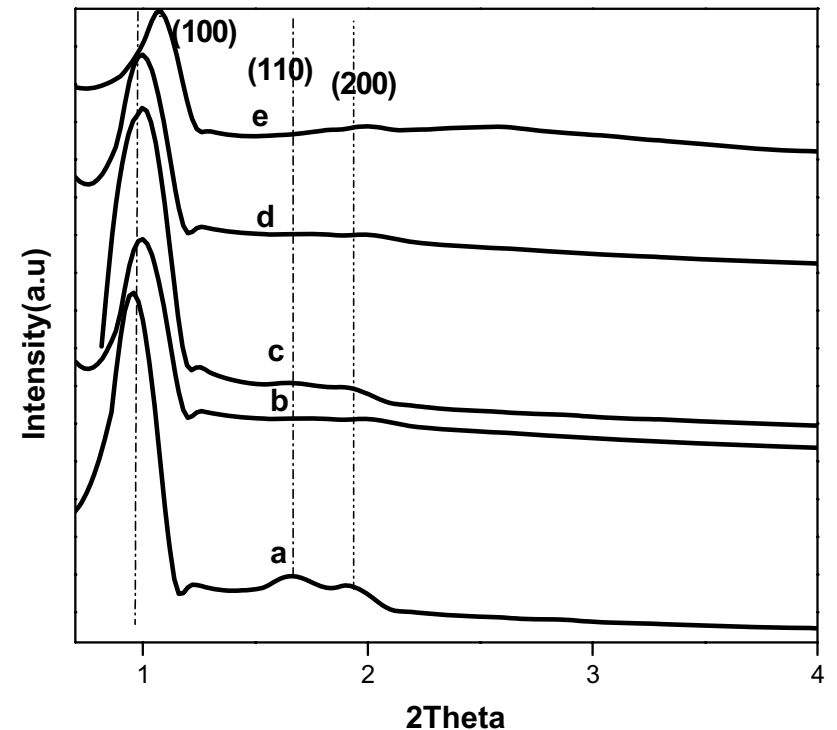

Fig. 2 Low-angle XRD profiles of various M/SBA-15(Si/M=20) catalysts. a Pure SBA- 15 , b Zr-SBA- 15 , c Nb-SBA-15, d Ti-SBA-15 and e Al-SBA- 15

the relative intensity of the (110) and (200) peaks decreased or disappeared after the introduction of metal into SBA-15, which might be due to the disruption of the textural uniformity, i.e., hexagonal structure of SBA-15 [25].

\section{Wide-angle XRD analysis}

The wide-angle $\mathrm{X}$-ray diffraction patterns of the calcined pure SBA-15 and metal-incorporated SBA-15 samples are shown in Fig. S2 (Supplementary Information). The XRD pattern of all the samples exhibits a broad reflection peak between $2 \theta=15^{\circ}-35^{\circ}$ due to amorphous silica [26]. Interestingly, the characteristic XRD peaks of incorporated metals are not appeared in the XRD pattern, suggesting that the incorporated metals were well dispersed on the SBA-15 support and no metal oxide crystallites were formed or the metal content was below the XRD detection limit.

\section{Scanning electron microscopy}

SEM analysis was used to investigate the surface physical morphology of pure SBA-15 and various metals-incorporated SBA-15 samples and the respective images are shown in Fig. 3. The pure SBA-15 sample showed earmarks of rice grains-like structure and the metal-incorporated samples exhibited irregular spherical-like morphology [27]. The morphology of the sample varies with the type of metals incorporated, since these materials were prepared by using a similar procedure and with the same metal precursors (all are isopropoxides) and the same $\mathrm{Si} / \mathrm{M}$ ratio except the nature of the metal $[28,29]$.

\section{FT-IR spectra}

The FT-IR spectra of pure SBA-15 and the metal-incorporated SBA-15 samples are shown in Fig. 4. All the samples exhibited IR bands in the region $3400-2400 \mathrm{~cm}^{-1}$ due to surface $-\mathrm{OH}$ groups and the IR band at $1630 \mathrm{~cm}^{-1}$ is assigned to the bending mode of the water molecule [30]. In general, the typical siliceous materials exhibit IR bands in the range of $400-2000 \mathrm{~cm}^{-1}$. The IR spectra of the pure SBA-15 sample exhibited the main IR band at $1080 \mathrm{~cm}^{-1}$ and weaker band at 800 and $960 \mathrm{~cm}^{-1}$ due to asymmetric and symmetric stretching modes of the $\mathrm{Si}-\mathrm{O}-\mathrm{Si}$ bond, respectively. In addition, a strong IR band at $458 \mathrm{~cm}^{-1}$ can be attributed to the rocking of the Si-O-Si bond. The IR spectra of all metalincorporated SBA-15 samples showed the IR bands similar to that of the pure SBA-15 sample. However, with close observation of the IR spectra of metal ions-incorporated SBA-15 samples, the intensity of the IR band at $960 \mathrm{~cm}^{-1}$ corresponds to the $\mathrm{Si}-\mathrm{O}-\mathrm{Si}$ bond decrease. It appears to be possible evidence of the isomorphism substitution of Si by metal ions $\left(\mathrm{Si}-\mathrm{O}^{-} \mathrm{M}^{+}\right)(\mathrm{M}: \mathrm{Zr}, \mathrm{Al}, \mathrm{Ti}$ and $\mathrm{Nb})$ [31]. Hence, the IR spectra gave evidence related to the formation of the $\mathrm{Si}-\mathrm{O}-\mathrm{M}$ bond in the metal-incorporated sample.

\section{UV-DRS analysis}

Generally, UV-Vis DRS analysis has been widely used to find the nature and coordination of metal ions in substituted molecular sieves. The UV-Vis DRS spectra of pure SBA-15 and metal-incorporated SBA-15 in the region of 200-800 $\mathrm{nm}$ are shown in Fig. S3 (Supplementary information). The pure SBA-15 showed no characteristic absorption band in the spectra, whereas all the metal-incorporated SBA-15 samples showed absorption bands in the region of $200-400 \mathrm{~nm}$ with different intensities depending on the metal incorporated.

The diffuse reflectance UV-visible spectra of the Ti-SBA-15 sample exhibited a very intense absorption band around $210-230 \mathrm{~nm}$ wavelength, characteristic of titanium ion $\left(\mathrm{Ti}^{4+}\right)$ present in the tetrahedral environment $[32,33]$. The intensity of the absorption peak decreased from $240 \mathrm{~nm}$ to $380 \mathrm{~nm}$ indicating the existence of less number of octahedral environment titanium $\left(\mathrm{Ti}^{6+}\right)$. In addition, the absence of the absorption band beyond $390 \mathrm{~nm}$ reveals the chance of existence of $\mathrm{TiO}_{2}$ in the form of anatase in the synthesised sample. The spectra of Zr-SBA-15 sample exhibited a band at $210 \mathrm{~nm}$ which could be responsible for transitions of eight coordinate tetravalent $\mathrm{Zr}\left(\mathrm{O}^{2-}-\mathrm{Zr}^{4+}\right)$ [34]. The absorption band at $210-240 \mathrm{~nm}$ for Nb-SBA-15 sample is attributed to the charge transfer band for the $\mathrm{O}^{2-}-\mathrm{Nb}^{+4}$. This result 
Fig. 3 SEM images of various metal-doped SBA-15 samples. a Pure SBA-15, b Zr-SBA-15, c Nb-SBA-15, d Ti-SBA-15 and e Al-SBA- 15
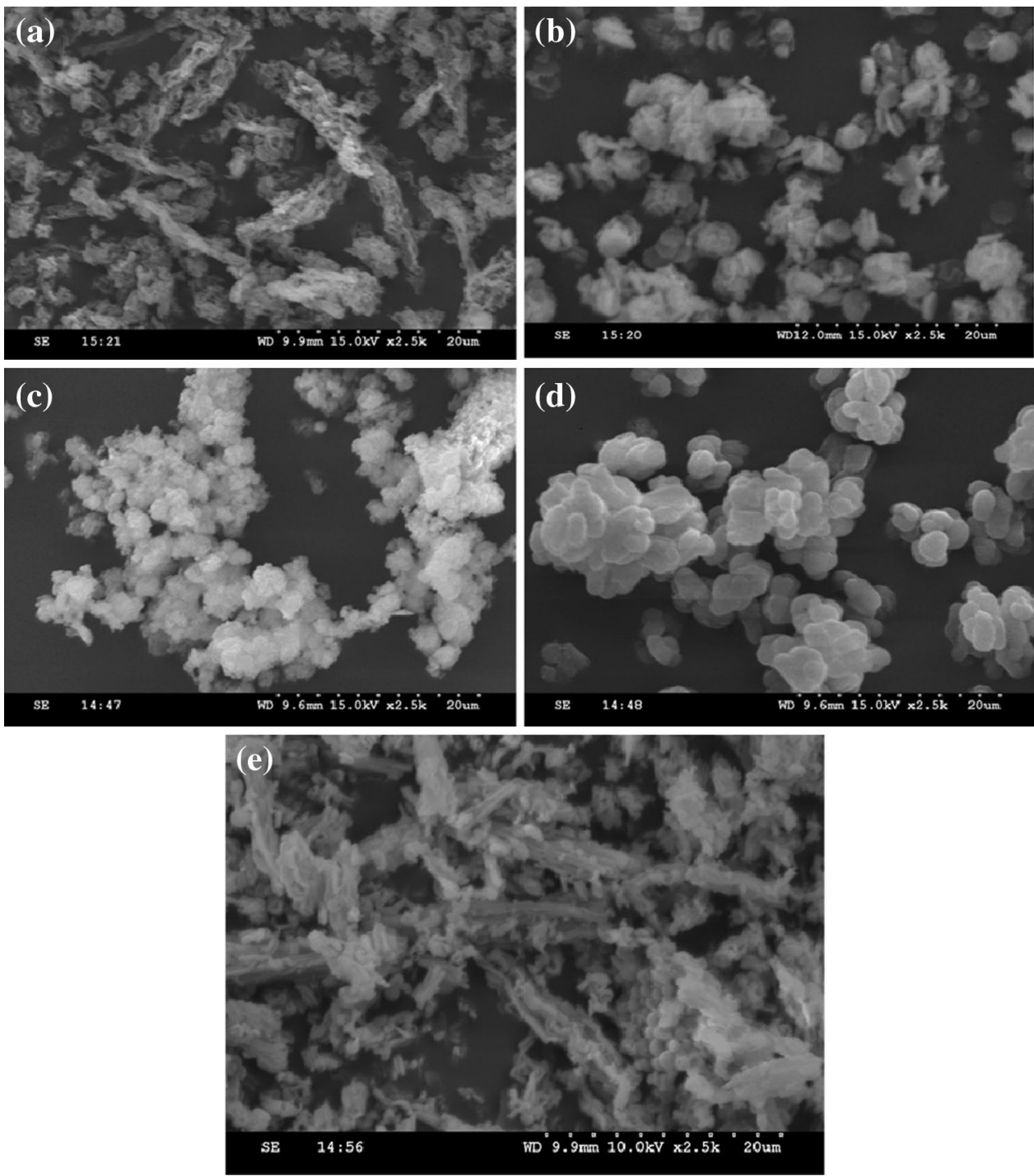

confirms the presence of the $\mathrm{Nb}$ species in the form of tetrahedral coordinate in the sample. The Al-SBA-15 sample showed an absorption band at $210 \mathrm{~nm}$, indicating that alumina is present in tetrahedral coordination in the SBA- 15 framework, along with a weak band at $260 \mathrm{~nm}$ due to the charge transfer transition of $\mathrm{Al}^{+3}-\mathrm{O}^{2-}$.

\section{Temperature-programmed desorption of ammonia ( $\mathrm{NH}_{3}$-TPD)}

In the present investigation, acidity measurements were carried out by the ammonia-TPD method. The ammoniaTPD profiles of the calcined samples of pure SBA-15 and metal-incorporated SBA-15 samples are presented in Fig. 5. Generally, the acidic strength of solid acid catalyst in the $\mathrm{NH}_{3}$-TPD profiles can be classified into three types depending on their strength in the temperature region of the TPD profile. These acidic sites are denoted as weak $\left(150-300{ }^{\circ} \mathrm{C}\right)$, moderate $\left(300-450{ }^{\circ} \mathrm{C}\right)$ and strong (450-650 ${ }^{\circ} \mathrm{C}$ ) [35]. Pure SBA-15 showed low-intensity broad peak in the medium and strong acidic region in the $\mathrm{NH}_{3}$-TPD measurements. In the case of metal-incorporated SBA-15 sample, the intensity of this peak, i.e., medium to strong acidic region increased in the $\mathrm{NH}_{3}$-TPD measurements for all samples irrespective of the type of metals. This mainly depends on the exposure of the incorporated metal over the surface of the SBA-15 and also the interaction between the metal and silica of SBA-15.

The ammonia uptake volumes are given in Table 1. As can be seen from the results in Table 1, the total acidity of the catalysts decreases in the following order: Nb-SBA$15>\mathrm{Zr}-\mathrm{SBA}-15>\mathrm{Al}-\mathrm{SBA}-15>\mathrm{Ti}-\mathrm{SBA}-15$. This result clearly indicates that the acidity of the catalysts was closely related to the nature of the metal incorporated in SBA-15, and niobium-incorporated SBA-15 showed higher number of medium to strong acidic sites compared to all other catalysts 


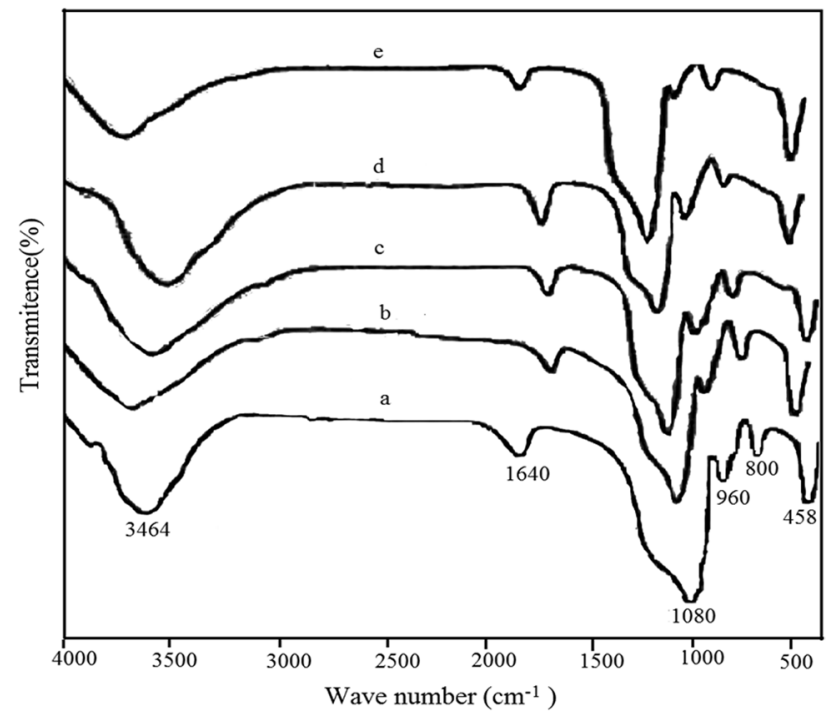

Fig. 4 FT-IR spectra of pure SBA-15 and various M/SBA-15 $(\mathrm{Si} / \mathrm{M}=20)$ catalysts. a Pure SBA- $15, \mathbf{b} \mathrm{Zr}-\mathrm{SBA}-15, \mathbf{c} \mathrm{Nb}-\mathrm{SBA}-15, \mathbf{d}$ Ti-SBA-15 and e Al-SBA-15

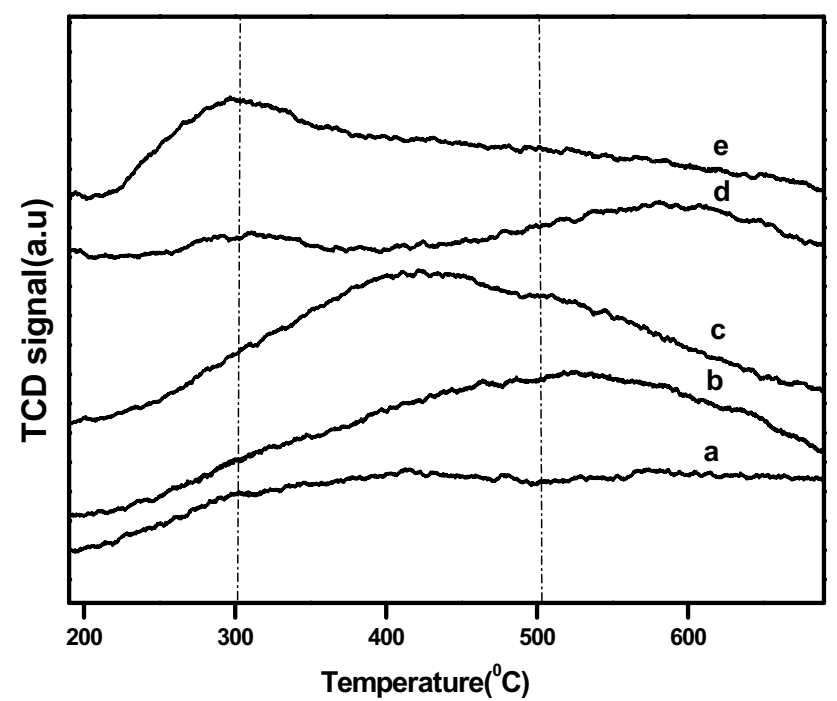

Fig. 5 TPD profiles of various M/SBA-15 $(\mathrm{Si} / \mathrm{M}=20)$ catalysts. a Pure SBA-15 b Zr-SBA-15 c Nb-SBA-15 d Ti-SBA-15 and e AlSBA-15

(Fig. 5). The acidity of the used catalysts after the acetalization reaction varied only to a marginal extent compared to samples before the reaction.

\section{Ex situ pyridine-adsorbed FT-IR analysis}

The ex situ pyridine-adsorbed FT-IR spectra of different metals incorporated into SBA-15 samples are illustrated in Fig. 6. Prior to FT-IR analysis, the catalyst samples were

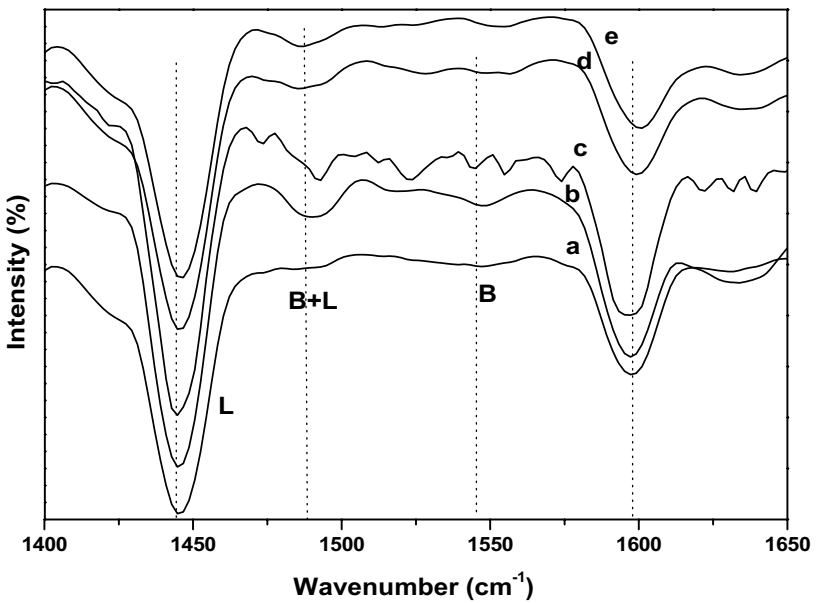

Fig. 6 Ex situ adsorbed profiles of various M/SBA-15 ( $\mathrm{Si} / \mathrm{M}=20)$ catalysts. a Pure SBA-15, b Nb-SBA-15, c Zr-SBA-15, d Ti-SBA-15 and $\mathbf{e} \mathrm{Al}-\mathrm{SBA}-15$

saturated with pyridine vapor at $200{ }^{\circ} \mathrm{C}$ for $2 \mathrm{~h}$. The ex situ pyridine-adsorbed IR profile of pure SBA-15 exhibited two peaks at 1444 and $1595 \mathrm{~cm}^{-1}$. Except these peaks, pure SBA-15 does not show any peaks, indicating the poor acidic nature of pure SBA-15. The weak acidic sites appearing in the pure SBA-15 profile is due to the silanol groups (Si-OH) of SBA-15 [36, 37]. Similar to the pure SBA-15 sample, the various metal-incorporated SBA-15 samples exhibited peaks at $1440-1450 \mathrm{~cm}^{-1}$. The intensive peaks are due to hydrogen-bonded pyridine with the sample and also one cannot exclude the existence of Lewis acidic sites of these samples, as both peaks appear in the same region. In addition, these samples exhibited peaks $1490-1500 \mathrm{~cm}^{-1}$, corresponding to a combination of both Brønsted and Lewis $(\mathrm{B}+\mathrm{L})$ acid sites, and at $1540-1548 \mathrm{~cm}^{-1}$, characteristic bands of Brønsted (B) acidic sites. The appearance of these peaks is probably due to the existence of the $\mathrm{Si}-\mathrm{O}-\mathrm{M}$ bond in the metal-incorporated SBA-15 sample. However, the intensity of these peaks is varied in different proportions depending on the nature of metal present in the catalyst. The intensity of the IR bands is proportional to the concentration of acidic sites. From the pyridine-adsorbed FT-IR spectra, the intensity of IR absorption bands at $1498 \mathrm{~cm}^{-1}(\mathrm{~B}+\mathrm{L})$ has increased in the following order: $\mathrm{Nb}-\mathrm{SBA}-15>\mathrm{Zr}-\mathrm{SBA}-$ $15>$ Ti-SBA-15 > Al-SBA-15. The intensity of the IR band at $1490-1500 \mathrm{~cm}^{-1}$ corresponds to the $(\mathrm{B}+\mathrm{L})$ acidity and shows the same trend of increase of the total acidity of the catalysts in TPD of ammonia. Interestingly, Zr-SBA-15 and Nb-SBA-15 catalysts showed significant amount of Brønsted (B) acidic peaks in the FT-IR profiles than the other samples. 


\section{Acetalization of glycerol}

The acetalization of glycerol with acetone over pure SBA-15 and various metals (M) incorporated on SBA-15 catalysts

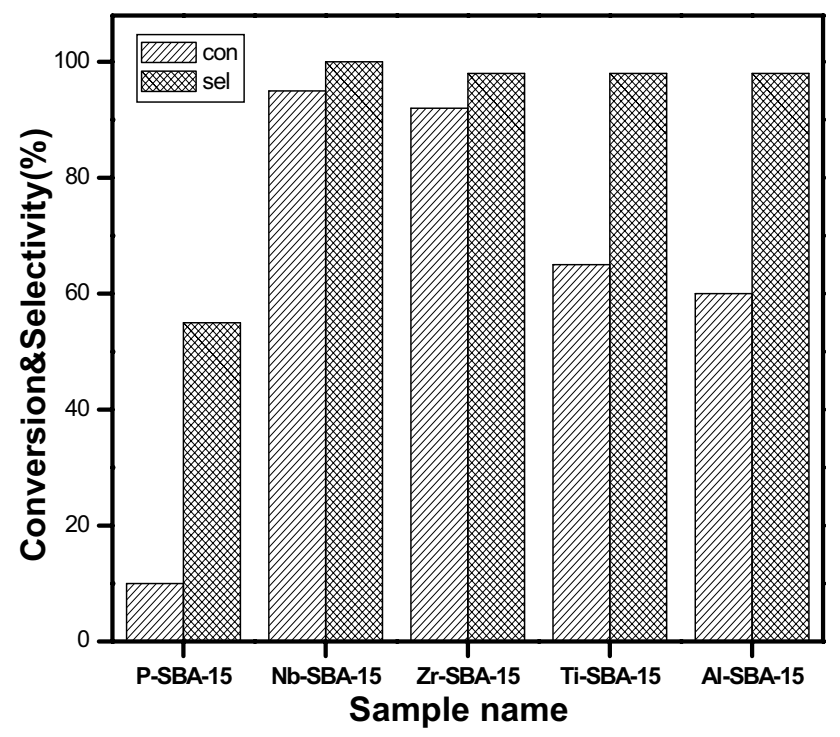

Fig. 7 Acetalization of glycerol with acetone over various M/SBA-15 $(\mathrm{Si} / \mathrm{M}=20)$ catalysts
$(\mathrm{M}=\mathrm{Zr}, \mathrm{Nb}, \mathrm{Ti}$ and $\mathrm{Al})$ were screened and the results are presented in Fig. 7. All the reactions were performed at room temperature for $1 \mathrm{~h}$ reaction time with $100 \mathrm{mg}$ catalyst amount and 3:1 molar ratio of acetone to glycerol. As can be seen from Fig. 7, pure SBA-15 sample showed 10\% glycerol conversion with $55 \%$ solketal selectivity. The Nb-SBA-15 and Zr-SBA-15 samples showed better glycerol conversion than Ti- and Al-incorporated SBA-15 samples, because Nb-SBA-15 and Zr-SBA-15 catalysts contain high surface area and acidity because the availability of the reacting molecules on the surface area is more compared to Al-SBA-15 and Ti-SBA-15. Among all the samples, the Nb-SBA-15 sample showed the highest activity, with a maximum conversion of $95 \%$ with $100 \%$ solketal selectivity. As expected, pure SBA-15 sample showed less activity for the acetalization reaction, probably due to its less acidic nature compared to other supported metal-incorporated catalysts. The blank reaction was also carried out without a catalyst, which resulted in very low glycerol conversion (less than $0.1 \%$ ).

These results clearly suggest the role of the catalyst in the acetalization of the glycerol.

The schematic representation of acetalization of glycerol with acetone over metal-incorporated SBA- 15 catalysts to (2, 2-dimethyl-1,3-dioxolan-4-yl) methanol (solketal) and 2, 2-dimethyl-1,3-dioxan-5-ol are shown in Scheme 1. In general, the acetalization reaction proceeds through the
Scheme 1 Schematic representation of the acetalization of glycerol with acetone<smiles>CC(C)=CCCOCC(O)CO</smiles>

Glycerol

Acetone

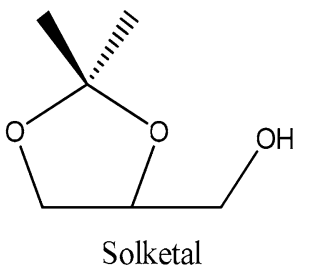<smiles>[3H][Ge]([3H])(CC(O)CO)C(C)(C)[O-]</smiles><smiles>CC(C)(O)OCC(O)CO</smiles>

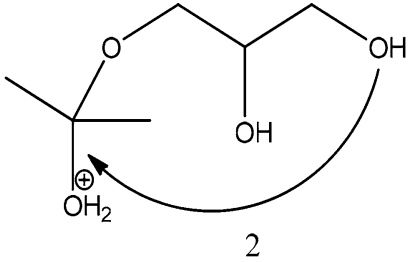

$\mathrm{OH}$<smiles>CC1(C)OCC(O)CO1</smiles>

2 
following two reversible reaction steps: a first step in which the alcohol group reacts with the acetone molecule, leading to the formation of the corresponding hemiacetal, i.e., unstable intermediate is formed. In the second step, the elimination of water molecule from one of the two hydroxyl groups of hemiacetal, leading to the formation of solketal and acetals [38]. Scheme 1 represents the detailed mechanism of acetalization of glycerol with acetone. Interestingly, the product formation (solketal and acetals) depends on the types of alcoholic $\left(1^{\circ}-\mathrm{OH}\right.$ or $\left.2^{\circ}-\mathrm{OH}\right)$ groups of the hemicatal involved in the reaction, i.e., if $1^{\circ}$ alcoholic groups are involved in the reaction, it produces a six-membered unstable transition state and leads to acetal as the product, and when $2^{\circ}$ alcoholic groups are involved in the reaction, it produces 5-membered stable transition state, leading to solketal as the product.

\section{Effect of molar ratio}

Table 2 shows the effect of acetone to glycerol molar ratio on glycerol acetalization over various metal-incorporated samples. The catalyst amount was kept constant. From Table 3, it can be seen that the glycerol conversion increased with the increase in acetone to glycerol ratio from 2:1 to 3:1. It is well known that the acetalization of glycerol to solketal is the equilibrium reaction and the excess amount of acetone is necessary to push the equilibrium toward the simultaneous enhancement of the conversion of glycerol. Moreover, the low amount of acetone could not disperse the glycerol homogeneously in the reaction medium, as this reaction was carried out in a solventless medium. With the increase of acetone to glycerol molar ratio further to $4: 1$ ratio, there was no significant change in the glycerol conversion observed, indicating that too much acetone does not influence glycerol conversion. By increasing the molar ratio, the active sites on the catalyst decrease due to their blockage with acetone on the surface of the catalyst. Hence, acetone to glycerol molar ratio of 3:1 was chosen for further reaction studies.

\section{Effect of catalyst amount}

To study the effect of catalyst amount on glycerol acetalization for various metal-incorporated SBA- 15 samples, the catalytic activity study was carried out at acetone to glycerol molar ratio 3:1 and the catalyst amount was varied from 25 to $100 \mathrm{mg}$. As expected, the conversion of glycerol increased with the increase of catalyst loading from 25 to $100 \mathrm{mg}$. This is due to the increase in the total number of acidic sites of the catalysts available for the acetalization of glycerol reaction. It is interesting to note that the selectivity of the product does not change with the amount of catalyst. Hence, the $100 \mathrm{mg}$ catalyst weight was chosen for further reaction studies.

Table 2 Effect of molar ratios on M/SBA-15 (Si/M=20) catalysts

\begin{tabular}{|c|c|c|c|c|c|c|}
\hline \multirow[t]{3}{*}{ Catalysts } & \multicolumn{6}{|c|}{ Acetone to glycerol molar ratio with catalyst } \\
\hline & \multicolumn{2}{|l|}{$2: 1$} & \multicolumn{2}{|l|}{$3: 1$} & \multicolumn{2}{|l|}{$4: 1$} \\
\hline & Conversion $(\%)$ & Selectivity (\%) & Conversion $(\%)$ & Selectivity (\%) & Conversion $(\%)$ & Selectivity $(\%)$ \\
\hline Blank test & $<0.1$ & & $<0.1$ & & $<0.1$ & \\
\hline $\mathrm{Nb}-\mathrm{SBA}-15$ & 65 & 98 & 95 & 100 & 97 & 90 \\
\hline $\mathrm{Zr}-\mathrm{SBA}-15$ & 75 & 98 & 92 & 98 & 94 & 88 \\
\hline Ti-SBA-15 & 32 & 98 & 65 & 98 & 70 & 88 \\
\hline Al-SBA-15 & 28 & 98 & 60 & 98 & 64 & 88 \\
\hline
\end{tabular}

Reaction conditions: Cat wt, $100 \mathrm{mg}$; time: $1 \mathrm{~h}$; room temperature

Table 3 Effect of catalyst amount on various M/SBA-15 $(\mathrm{Si} / \mathrm{M}=20)$ catalysts

\begin{tabular}{|c|c|c|c|c|c|c|}
\hline \multirow[t]{3}{*}{ Catalysts } & \multicolumn{6}{|c|}{ Catalyst amount } \\
\hline & \multicolumn{2}{|l|}{$25 \mathrm{mg}$} & \multicolumn{2}{|l|}{$50 \mathrm{mg}$} & \multicolumn{2}{|l|}{$100 \mathrm{mg}$} \\
\hline & $\begin{array}{l}\text { Conver- } \\
\text { sion (\%) }\end{array}$ & Selectivity (\%) & $\begin{array}{l}\text { Conver- } \\
\text { sion (\%) }\end{array}$ & Selectivity (\%) & $\begin{array}{l}\text { Conver- } \\
\text { sion (\%) }\end{array}$ & Selectivity (\%) \\
\hline Nb-SBA-15 & 62 & 98 & 72 & 98 & 95 & 100 \\
\hline Zr-SBA-15 & 64 & 98 & 78 & 98 & 92 & 98 \\
\hline Ti-SBA-15 & 36 & 98 & 40 & 98 & 65 & 98 \\
\hline Al-SBA-15 & 30 & 98 & 35 & 98 & 60 & 98 \\
\hline
\end{tabular}

Reaction conditions: acetone and glycerol ratio: $3: 1$; time: $1 \mathrm{~h}$; room temperature 


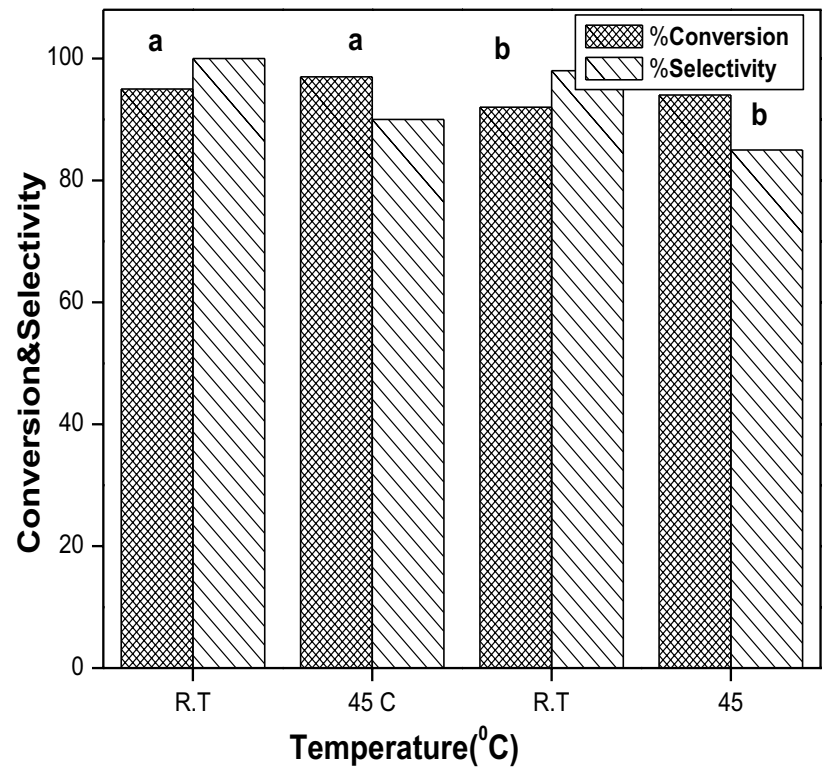

Fig. 8 Effect of reaction temperature over the Nb-SBA-15 and $\mathrm{Zr}-$ SBA-15 samples. a Nb-SBA-15 and b Zr-SBA-15

\section{Effect of temperature}

An attempt also been made to study the impact of reaction temperature on the conversion and selectivity of the products using Nb-SBA-15 and Zr-SBA-15 samples to find out the optimum conditions for maximum yield and the results are shown in Fig. 8. As can be seen from Fig. 8, there is an increase in the conversion of glycerol with increase of reaction temperature from room temperature (R.T) to $45^{\circ} \mathrm{C}$. However, the formation of a five-member ring acetal (solketal) was decreased as the temperature increased from RT to $45{ }^{\circ} \mathrm{C}$. These findings can explain the favorable formation of the five-membered ring acetal (solketal) at room temperature and its formation was decreased with the rise of temperature $\left(45^{\circ} \mathrm{C}\right)$. This is most likely due to the differene in formation energy of the compound which is strongly dependent on the reaction temperature. The observed results in this study are in good agreement with the results reported in literature [39]. From this result, one can easily conclude that the room temperature is the best reaction temperature for the formation of solketal.

\section{Catalyst stability tests}

To know about the stability of the catalysts, the reusability study was carried out for the Nb-SBA-15 and Zr-SBA-15 samples. After each run, the sample was separated by centrifugation and washed with methanol followed by drying it in an oven at $100{ }^{\circ} \mathrm{C}$ for $10 \mathrm{~h}$. Thereafter, the reaction was carried out with the spent sample by using the same reaction conditions mentioned in "Experimental section". This
Table 4 The catalytic activities of the fresh and reused catalysts

\begin{tabular}{|c|c|c|c|c|}
\hline \multirow[t]{3}{*}{ Number of runs } & \multicolumn{4}{|l|}{ Catalyst } \\
\hline & \multicolumn{2}{|c|}{ Nb-SBA-15 } & \multicolumn{2}{|c|}{$\mathrm{Zr}-\mathrm{SBA}-15$} \\
\hline & $\begin{array}{l}\text { Con- } \\
\text { version } \\
(\%)\end{array}$ & Selectivity (\%) & $\begin{array}{l}\text { Con- } \\
\text { version } \\
(\%)\end{array}$ & Selectivity (\%) \\
\hline Run1 & 95 & 100 & 92 & 98 \\
\hline Run2 & 90 & 100 & 85 & 98 \\
\hline Run3 & 82 & 97 & 78 & 95 \\
\hline Run4 & 80 & 94 & 75 & 95 \\
\hline
\end{tabular}

Reaction conditions: acetone and glycerol ratio: 3:1; cat wt: $100 \mathrm{mg}$,;ime: $1 \mathrm{~h}$; room temperature

procedure was repeated to test the reusability of the catalyst by recycling it through four consecutive batch runs and the results are presented in Table 4. The conversion of glycerol and selectivity of solketal for the Nb-SBA-15 sample during the first run was found to be 95 and $100 \%$, respectively, and it was decreased to 80 and $94 \%$ in the fourth run. However, Zr-SBA-15 sample exhibited glycerol conversion around 92 with $98 \%$ selectivity toward solketal in the first run. This has been considerably decreased to $75 \%$ conversion and $95 \%$ solketal selectivity in the fourth run. In the case of Ti-SBA15 , the conversion of glycerol and selectivity of solketal decreased from 65 to $98 \%$ for the first run to 30 and $70 \%$ respectively, for the second run. Further experiments with Al-SBA-15 sample show that the conversion of glycerol and selectivity of solketal decreased from 60 to $98 \%$ for the first run to 26 and $70 \%$ in the second run. The decrease of solketal selectivity increases the formation of the by-product (acetal). Though there was slight reduction in the catalytic activities of these samples (Nb-SBA-15 and Zr-SBA-15), it showed an excellent stability in its catalyst activity in the fourth run, while in the second run only these two samples (Ti-SBA-15 and Al-SBA-15) showed considerable decrease of glycerol conversion and selectivity of solketal. These results clearly suggest that Nb-SBA- 15 and $\mathrm{Zr}-\mathrm{SBA}-15$ are the most industrially viable heterogeneous catalysts for the synthesis of oxygenated fuel additives.

\section{Spent sample characterization}

The surface acidity of the spent catalyst (Nb-SBA-15, Zr-SBA-15) (Fig. S4) and the total acidities are mentioned in Table 1. From the TPD profiles, the acidic strength was decreased for the spent samples than the fresh ones. Ex situ pyridine-adsorbed FT-IR analysis (Fig. S5) was also performed to examine the acidic properties of the spent (Nb-SBA-15, Zr-SBA-15) catalysts. The band intensities corresponding to Brønsted (B) and $\mathrm{B}+\mathrm{L}$ acidic sites of spent catalysts were decreased compared to the fresh catalyst. 
The ICP-AES analysis (Table 1) of the spent samples shows minor variation in the metal content compared to the fresh catalyst. The XRD peaks of the spent catalyst (Nb-SBA-15, $\mathrm{Zr}-\mathrm{SBA}-15$ ) (Fig. S6) intensity decreased compared to the fresh catalyst. The BET surface area (Table 1) of the spent catalyst also decreased compared to the fresh catalyst. The BJH isotherm (Fig. S1) of the spent samples are in a broad range rather than the narrow size in the case of fresh samples. Due to decreasing surface area and acidity of the spent catalyst, the activity of the catalyst decreased.

\section{Conclusion}

The acetalization of glycerol with acetone was investigated over metal-incorporated mesoporous silica (M-SBA-15) as a solid acid catalyst. The results of XRD and $\mathrm{N}_{2}$ sorption studies suggest that the hexagonal arrangement of the SBA-15 frameworks was retained after metal incorporation by one-pot synthesis of M-SBA-15. FT-IR and UV-DRS results showed the presence of the $\mathrm{M}-\mathrm{O}-\mathrm{Si}$ framework in the M-SBA-15 materials. The metal-incorporated SBA-15 acid catalysts described herein are novel and selective heterogeneous catalysts for the preparation of solketal from glycerol. All the reaction parameters (temperature, time, catalyst loading and glycerol to acetic acid molar ratio) have been optimized to obtain the highest activity to catalytic conversion of glycerol. The catalytic activity during the acetalization of glycerol depends on the nature of the surface acidic properties and also on the surface properties of the M-SBA-15 catalysts. All the catalysts exhibited an excellent selectivity of $>90 \%$ toward solketal formation during acetalization of glycerol. The Nb-SBA-15 exhibited the best performance with the highest conversion and selectivity among several catalysts examined. The study indicates that glycerol conversion and selectivity to reaction products depends not only on the reaction parameters, but also can be influenced by the acidic and textural properties of the catalysts. The reusability studies reveal that the M-SBA-15 catalysts are highly stable even after the fourth reaction run for the acetalization of glycerol as evidenced by the characterization of spent catalysts.

Acknowledgements KVR thanks the CSIR-HRD group, New Delhi, for funding under the Emeritus Scientist Scheme. SA thanks UGC for the award of Senior Research Fellowship.

Open Access This article is distributed under the terms of the Creative Commons Attribution 4.0 International License (http://creativeco mmons.org/licenses/by/4.0/), which permits unrestricted use, distribution, and reproduction in any medium, provided you give appropriate credit to the original author(s) and the source, provide a link to the Creative Commons license, and indicate if changes were made.

\section{References}

1. Manjunathan P, Maradur SP, Halger AB, Shanbhag GV (2015) Room temperature synthesis of solketal from acetalization of glycerol with acetone: Effect of crystallite size and the role of acidity of beta zeolite. J Mol Catal A 396:47-54

2. Vieira LH, Carvalho KTG, Gonzalez EAU, Pulcinelli SH, Santilli CV and Martins L (2015) Effects of crystal size, acidity and synthesis procedure on the catalytic performance of gallium and aluminum MFI zeolites in glyceroldehydration. J Mol Catal A

3. Narkhede N, Patel A (2016) Sustainable valorisation of glycerol via acetalization as well as carboxylation reactions over silicotungstates anchored to zeolite H $\beta$. Appl Catal A 515:154-163

4. Katryniok B, Paul S, Baca VB, Rey P, Dumeignil F (2010) Glycerol dehydration to acrolein in the context of new uses of glycerol. Green Chem 12:2079-2098

5. Cecilia JA, Sancho CG, Robles JMM, Gonzalez JS, Tost RM, Torres PM (2016) WO3supported on $\mathrm{Zr}$ doped mesoporous SBA-15 silica for glycerol dehydration to acrolein. Appl Catal A 516:30-40

6. Goncalves VLC, Pinto BP, Silva JC, Mota CJA (2008) Acetylation of glycerol catalyzed by different solid acids. Catal Today 133-135:673-677

7. Khayoon MS, Hameed BH (2013) Solventless acetalization of glycerol with acetone to fuel oxygenates over $\mathrm{Ni}-\mathrm{Zr}$ supported on mesoporous activated carbon catalyst. Appl Catal A 464-465:191-199

8. Rao GS, Rajan NP, HariSekhar M, Ammaji S, Chary KVR (2014) Porous zirconium phosphate supported tungsten oxide solid acid catalysts for the vapour phase dehydration of glycerol. J Mol Catal A 395:486-493

9. Chen L, Nohair B, Kaliaguine S (2016) Glycerol acetalization with formaldehyde using water-tolerant s olidacids. Appl Catal A 509:143-152

10. Umbarkar SB, Kotbagi TV, Biradar AV, Pasricha R, Chanale J, Dongare MK, Mamede AS, Lancelot C, Payen E (2009) Acetalization of glycerol using mesoporous $\mathrm{MoO}_{3} / \mathrm{SiO}_{2}$ solid acid catalyst. J Mol Catal A 310:150-158

11. Kus JK, Held A, Nowinska K (2016) Enhancement of the catalytic activity of H-ZSM-5 zeolites for glycerol acetalization by mechanical grinding. Reac Kinet Mech Cat 117:341-352

12. Kanezashi M, Brien JO, Lin YS (2007) Thermal stability improvement of MFI-type zeolite membranes with doped zirconia intermediate layer. Microporous Mesoporous Mater 103:302-308

13. Sailaja G, Rajan NP, Rao GS, Chary KVR (2015) Acetalization of glycerol with acetone to bio fuel additives oversupported molybdenum phosphate catalysts. J Mol Catal A 410:49-57

14. Ziarani GM, Lashgari N, Badiei A (2015) Sulfonic acid-functionalized mesoporous silica (SBA-Pr- $\mathrm{SO} 3 \mathrm{H}$ ) as solid acid catalyst in organic reactions. J Mol Catal A 397:166-191

15. Tao M, Meng X, Xin Z, Bian Z, Lv Y, Gu J (2016) Synthesis and characterization of well dispersed nickel-incorporated SBA-15 and its high activity in syngas methanation reaction. Appl Catal A 516:127-134

16. Doustkhah E, Rostamnia S (2016) Covalently bonded zwitterionic sulfamic acid onto the SBA- 15(SBA-15/PrEn-NHSO ${ }_{3} \mathrm{H}$ ) reveals good Bronsted acidity behavior and catalytic activity in N-formylation of amines. J Mol Catal A 411:317-324

17. Garcia JRR, Medrano VGB, Giraldo SA (2016) Improving the selectivity in hydro cracking of phenanthrene over mesoporous Al-SBA- 15 based Fe-W catalysts by enhancing mesoporosity and acidity. Appl Catal A 510:98-109

18. Arellano CG, Aranconb RAD, Luque R (2014) Al-SBA-15 catalysed cross-esterification and acetalisation of biomass-derived platform chemicals. Green Chem 16:4985-4993

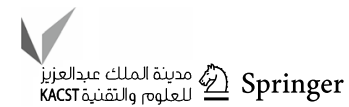


19. Mutlu VN, Yilmaz S (2016) Esterification of cetyl alcohol with palmitic acid over WO3/Zr-SBA-15 and Zr-SBA-15 catalysts. Appl Catal A 522:194-200

20. Yokoi T, Yoshitake H, Tatsumi T (2004) Synthesis of amino-functionalized MCM-41 via direct co- condensation and post-synthesis grafting methods using mono-, di- and tri-amino-organoalkoxysilanes. J Mater Chem 14:951-957

21. Escola JM, Moreno J, Rodríguez R, Grieken RV (2009) Direct synthesis of mesoporous M-SBA-15 (M=Al, Fe, B, Cr) and application to 1-hexene oligomerization. Chem Eng $\mathrm{J}$ 155:442-450

22. Srinivas M, Raveendra G, Parameswaram G, Sai Prasad PS, Lingaiah N (2016) Cesium exchanged tungstophosphoric acid supported on tin oxide: an efficient solid acid catalyst for etherification of glycerol with tert-butanol to synthesize biofuel additives. J Mol Catal A 413:7-14

23. Yue Y, Gedeon A, Bonardet JL, Melosh N, Espinose JBD and Fraissard J (1999) Direct synthesis of Al- SBA-15 mesoporous molecular sieves: characterization and catalytic activities. Chem Commun 1967-1968

24. Wang J, Liu Q (2008) A simple method to directly synthesize AlSBA-15 mesoporous materials with different Alcontents. Solid State Commun 148:529-533

25. Erdem S, Erdem B, Oksuzolu RS, Citak A (2013) Bifunctional Fe-SBA-15-SO3H Mesoporous Catalysts with Different $\mathrm{Si} / \mathrm{Fe}$ Molar Ratios: Synthesis. Characterization and Catalytic Activity Bull Korean Chem Soc 34:1481-1486

26. Rossinyol E, Arbio J, Peiro F, Cornet A, Morante JR, Tian B, Bo T, Zhao D (2005) Nanostructured metal oxides synthesized by hard template method for gas sensing applications. Sens Actuators B 109:57-63

27. Margolese D, Melero JA, Christiansen SC, Chmelka BF, Stucky GD (2000) Direct syntheses of ordered SBA-15 mesoporous silica containing sulfonic acid groups. Chem Mater 12:2448-2459

28. Li W, Huang SJ, Liu SB, Coppens MO (2005) Influence of the Al source and synthesis of ordered Al-SBA- 15 hexagonal particles with nanostairs and terraces. Langmuir 21:2078-2085

29. Ye W, Lin Z, Dong B, Kang J, Wang X, Zheng X (2011) Preparation and catalytic properties of Ti- SBA-15 mesoporous materials. Mater Sci Appl 2:661-668
30. Clearfield A, Thakur DS (1986) Zirconium and titanium phosphates as catalyst: a review. Appl Catal 26:1-26

31. Selvaraj M, Kim BH, Lee TG (2005) FTIR studies on selected mesoporous metallosilicate molecular sieves. Chem Lett 34:1290-1291

32. Vinu A, Srinivasu P, Miyahara M, Ariga K (2006) Preparation and catalytic performances of ultralarge-pore TiSBA-15 mesoporous molecular sieves with very high Ti content. J Phys Chem B 110:801-806

33. Newalkar BL, Olanrewaju J, Komarneni S (2001) Direct synthesis of titanium-substituted mesoporous SBA-15 molecular sieve under microwave-hydrothermal conditions. Chem Mater 13:552-557

34. Newalkar BL, Olanrewaju J, Komarneni S (2001) Microwavehydrothermal synthesis and characterization of zirconium substituted SBA-15 mesoporous silica. J Phys Chem B 105:8356-8360

35. De Oliveira AS, Vasconcelos SJS, de Sousa JR, de Sousa FF, Filho JM, Oliveira AC (2011) Catalytic conversion of glycerol to acrolein over modified molecular sieves: activity and deactivation studies. Chem Eng J 168:765-774

36. Parry EP (1963) An infrared study of pyridine adsorbed on acidic solids. Characterization of surface acidity. J Catal 2:371-379

37. Emeis CA (1993) Determination of integrated molar extinction coefficients for infrared absorption bands of pyridine adsorbed on solid acid catalysts. J Catal 141:347-354

38. Vicente G, Melero JA, Morales G, Paniagua M, Martin E (2010) Acetalisation of bio- glycerol with acetone to produce solketal over sulfonic mesostructured silicas. Green Chem 12:899-907

39. Khayoon MS, Abbas A, Hameed BH, Triwahyono S, Jalil AA, Harris AT, Minett AI (2014) Selective acetalization of glycerol with acetone over nickel nanoparticles supported on multi-walled carbon nanotubes. Catal Lett 144:1009-1015

Publisher's Note Springer Nature remains neutral with regard to jurisdictional claims in published maps and institutional affiliations. 